\title{
Laser Irradiation Induces DNA Polymorphism and Alters Phytochemicals Compositions as well as Growth and Yield of Curcuma longa
}

\author{
Fadia El-Sherif ${ }^{1,2, ~ *, ~ Y u n-K i a m ~ Y a p ~}{ }^{1}$, Hairul Islam Ibrahim ${ }^{1}$ \\ ${ }^{1}$ Department of Biological Sciences, College of Science, King Faisal University, Al-Ahsaa, Kingdom of Saudi Arabia \\ ${ }^{2}$ Department of Horticulture, Faculty of Agriculture, Suez Canal University, Ismailia, Egypt
}

Email address:

felsherif@kfu.edu.sa (F. El-Sherif)

${ }^{*}$ Corresponding author

\section{To cite this article:}

Fadia El-Sherif, Yun-Kiam Yap, Hairul Islam Ibrahim. Laser Irradiation Induces DNA Polymorphism and Alters Phytochemicals Compositions as well as Growth and Yield of Curcuma longa. Journal of Diseases and Medicinal Plants. Vol. 5, No. 2, 2019, pp. $29-38$. doi: $10.11648 /$ j.jdmp.20190502.12

Received: April 15, 2019; Accepted: May 23, 2019; Published: June 5, 2019

\begin{abstract}
Curcuma longa, commonly known as curcuma or turmeric is a perennial herbaceous plant native to Indian subcontinent and Southeast Asia. Its underground part, referred as rhizome, is used for vegetative propagation and source for remedies for various illnesses. Curcuminoid and volatile oils are the major active components found in turmeric, the yellow power obtained from the ground rhizome. He-Ne laser irradiation has been used as biostimulator device to enhance plant growth. In this study, we have pre-treated the curcuma rhizomes with 5, 10- or 15-min He-Ne laser irradiation. Laser pre-treated and non-treated rhizomes were then cultivated in greenhouse for 8 months. The growth parameters, photosynthetic pigment contents, rhizomes yield were measured. The phytochemical compositions of rhizomes from different treatment groups were measured by gas chromatography mass spectrometry and compared. Effects of laser on DNA polymorphism was assessed by ISSR markers. Our results indicated that laser pre-treatments on rhizomes enhanced curcuma plant height, number of roots and rhizomes, rhizomes diameters, and dried weight of leaves and rhizomes, as well as photosynthetic pigments. The enhancement effects are more prominent in $10 \mathrm{~min}$ treatment groups. In addition, laser treatment also alters the phytochemical compositions of ethanol extract from the rhizomes. Interestingly, our study has revealed that laser treatment had resulted in DNA polymorphism as shown from the analysis by ISSR markers.
\end{abstract}

Keywords: Laser, Curcuma longa, Turmeric, Rhizome Yield, Chlorophyll, Gas Chromatography Mass Spectrometry, ISSR

\section{Introduction}

Curcuma longa of Zingiberaceae family is commonly known as curcuma or turmeric. It is a perennial herbaceous plant, native in the Indian subcontinent and Southeast Asia. The underground part of curcuma plants contains the rhizome, which is used for vegetative propagation of the plants. The rhizome is also used as spices and remedies. Different traditional therapeutic applications of turmeric can be found in many literatures as reviewed by Prasad and Aggarwal [1] and Gupta, Kismali [2]. Curcuminoid and volatile oil are the two groups of active components in turmeric. Curcuminoid is phenolic compounds, composed of curcumin and its derivatives dimethoxy curcumin and bis-demethoxy curcumin [3]. Curcuminoid is responsible for the biological activities of turmeric extracts [4]. Scientific studies on the antioxidant, anti-inflammatory, antimutagenic, antimicrobial, and anticancer activities of turmeric extracts in different in-vitro and in-vivo systems have been reviewed by Prasad and Aggarwal [1]. The therapeutic effects of turmeric in human studies, for example the effects of turmeric extracts on asthma, irritable bowel syndrome, peptic ulcer, and colicky abdominal pain were also discussed in the same review.

Laser irradiation as a "biostimulator device" has dated back to the 70s when Wilde et. al. [5] and Paleg and Aspinall [6] 
had used ruby laser and He-Ne laser respectively to speed up the germination and growth of plants. Laser light wavelength most often used in the bio-stimulation process is the red light such as those produced by the He-Ne laser. An extensive list of different laser devises that have been used as biostimulator devise in plant growth was compiled by Hernandez et al [7]. In addition to this list, recent studies on wheat [8], soy bean [9, 10], sunflower [11], Celosia argentea [12], or vegetables and herbs such as fennel, coriander, anise, cumin, sweet basil, scorzonera, moringa and sage [13-18] have provided numerous evidences on the laser bio-stimulation effects ranging from increase germination rate, to plant growth, as well as enhancement and increase in secondary metabolites compounds.

DNA markers have been an indispensable tool in plant molecular breeding $[19,20]$ and identification of genetic diversity [21]. Among many DNA markers, ISSR offers the advantages that no prior knowledge of genomic sequence is required in primer design. In addition to the above application, numerous reports on the use of ISSR for identification of DNA polymorphism in mutant populations induced in the tissue culture studies of crops, flower, herbs and vegetables plants [22-26] have also been documented. ISSR markers have also been used Singh et. al. [27] and Saha et. al. [28] in accessing the genetic diversity of curcuma.

In this study, air-dried Curcuma longa rhizomes was exposed to $\mathrm{He}-\mathrm{Ne}$ laser irradiation for 5-, 10- and $15 \mathrm{~min}$ before planting to study the effects of laser pretreatments on the growth, yield of the resulting curcuma plants. The chemical compositions of the ethanol extract prepared from the rhizomes of these plants were analyzed by gas chromatography mass spectroscopy (GC-MS). DNAs were extracted from the leaves of these plants and analyzed using ISSR markers to detect the presence of DNA polymorphism among the treatment groups.

\section{Materials and Methods}

\subsection{He-Ne Laser Irradiation}

Air-dried Curcuma longa rhizomes was obtained from Sekem Company, Cairo, Egypt. The rhizomes of about $1 \mathrm{~cm}$ in length with a single node were divided into four groups (control, 5-, 10- and 15 min laser irradiation), with 10 pieces of rhizomes per group. The "control" group rhizomes were not treated with laser ray. The He-Ne ray was produced from a laser beam (Department of Physics, College of Science, King Faisal University) with $632 \mathrm{~nm}$ wavelength, and a density power of $5.5 \mathrm{~mW} / \mathrm{mm}^{2}$. The rhizome was placed in a petri dish and irradiated with the ray from a distance of $40 \mathrm{~mm}$ on top of the rhizome for 5-, 10- or 15 min respectively.

\subsection{Curcuma Cultivation in Greenhouse}

The experiment was conducted under greenhouse conditions during the two successive seasons in 2016 and 2017 at Agriculture and Veterinary Research and Training center, King Faisal University. During the experiment, temperature between $32-36^{\circ} \mathrm{C}$ and relative humidity of $47-56 \%$, with $14 \mathrm{~h}$ average photoperiod was recorded. Rhizomes were sown on April $1^{\text {st }}$ in both 2016 and 2017. The germination was carried out by sowing rhizomes in trays (depth of 1.0-2.0 cm.) filled with a moist mixture of (1:1 v:v) sand and peat moss. Seedlings of turmeric $(5 \mathrm{~cm})$ in height and carrying three pairs of leaves were transplanted to sandy soil, by placing the seedling $40 \times 40 \mathrm{~cm}$ apart from each other's. Irrigation, fertilization and weeding were performed as recommended. The chemical contents of the irrigation water are tabulated in Table 1. After eight months of cultivation, the whole plant was harvested, plant height $(\mathrm{cm})$, number of leaves (n), number of roots and rhizomes / plant (n), dry weight of leaves, roots and rhizomes / plant $(\mathrm{g})$ and rhizomes diameter $(\mathrm{mm})$ were recorded using 6 random plants from each treatment group.

Table 1. Chemical content of the irrigation water.

\begin{tabular}{|c|c|c|c|c|c|c|c|c|c|}
\hline \multirow{2}{*}{$\begin{array}{l}\text { Salinity Level } \\
\left(\mathrm{mS} \mathrm{cm}^{-1}\right)\end{array}$} & \multicolumn{2}{|c|}{ Cations $\left(\right.$ meq L $\left.^{-1}\right)$} & \multicolumn{6}{|c|}{ Anions (meq $\mathrm{L}^{-1}$ ) } & \multirow[b]{2}{*}{ SAR } \\
\hline & $\mathrm{Ca}^{2+}$ & $\mathrm{Mg}^{2+}$ & $\mathrm{Na}^{+}$ & $\mathbf{K}^{+}$ & $\mathrm{CO}_{3}{ }^{2-}$ & $\mathrm{HCO}_{3}^{-}$ & $\mathrm{SO}_{4}{ }^{2-}$ & $\mathrm{Cl}^{-}$ & \\
\hline 1.35 & 5.72 & 2.02 & 7.27 & 0.38 & 0.28 & 2.68 & 4.03 & 8.4 & 3.43 \\
\hline
\end{tabular}

\subsection{Measurement of Photosynthetic Pigment}

The $3^{\text {rd }}$ bottom fresh leaf from 6 randomly selected 7-months old turmeric plants were excised. The amount of chlorophyll $\mathrm{a}, \mathrm{b}$ and carotenoid were measured as described by A. O. A. C [29] with $80 \%$ acetone. The measurement of absorbance was performed using the Agilent $8453 \mathrm{UV}$-visible Spectrophotometer.

\subsection{GC/MS Analysis}

The GC/MS analysis was accomplished at the Mass spectrometry Experimental Nuclear Physics Dept, NRC, Cairo, Egypt.

\subsubsection{Sample Preparation}

One gram of the homogenized air-dried rhizome powder of 3 randomly selected turmeric plants from each treatment group (control, 10- and 15 min laser irradiation) planted in the second season was added to a $28-\mathrm{ml}$ stoppered culture tube and defatted by $30-\mathrm{ml}$ of ethanol for one day with shaking at $100 \mathrm{rpm}$ on a rotary shaker. The extracts were filtered through a $0.2 \mu \mathrm{m}$ syringe filter and $2 \mu \mathrm{L}$ was injected into the GC/MS system.

\subsubsection{Instrumentation and Separation Conditions}

GC 1310-ISQ mass spectrometer (Thermo Scientific, Austin, TX, USA) with a direct capillary column TG-35MS (30 m x $0.25 \mathrm{~mm} \times 0.25 \mu \mathrm{m}$ film thickness) was used. The separation of active compounds was performed according to Salem, Zayed [30]

\subsubsection{Identification of Components}

Active compounds were identified using the database of National Institute Standard and Technology (NIST). The components were identified by comparison of their retention times 
and mass spectra with NIST 11 mass spectral database [31].

\subsection{Genomic DNA Extraction and ISSR-PCR Analysis}

\subsubsection{Genomic DNA Extraction}

Genomic DNA was extracted from 3 randomly selected 2-months old turmeric plants leaf samples (second season plants) from each treatment group using Qiagen-DNA mini kit (cat. no. 51306).

\subsubsection{ISSR-PCR Analysis}

Genomic DNA from leaf samples of 3 individual plants from each treatment were combined to perform the ISSR-PCR. ISSR-PCR was performed in $25 \mu \mathrm{L}$ reaction mix containing $10 \times \mathrm{PCR}$ buffer, $2 \mathrm{mM} \mathrm{MgC1} 1_{2}, 0.25 \mathrm{mM}$ of each dNTPs, 10 pM oligonucleotide primer (Table 2), 400 ng genomic DNA and 0.25 unit of hot start Taq DNA polymerase (Invitrogen). A hot start thermocycling profile was performed as follows: initial denaturation step of $5 \mathrm{~min}$ at $94^{\circ} \mathrm{C}$, followed by 35 cycles of 1 min denaturation at $94^{\circ} \mathrm{C}, 45 \mathrm{sec}$ annealing at $51-55^{\circ} \mathrm{C}$ (annealing temperature for each primer was calculated according to its sequence composition $[\mathrm{Tm}=4(\mathrm{G}+\mathrm{C})+2(\mathrm{~A}+\mathrm{T})-3 \mathrm{C}])$, followed by extension at $72^{\circ} \mathrm{C}$ for $1 \mathrm{~min}$ and a final extension at $72^{\circ} \mathrm{C}$ for $8 \mathrm{~min}$. The products were kept at a hold temperature of $4{ }^{\circ} \mathrm{C}$. The PCR products were separated on $1.2 \%$ agarose gel, stained with $0.5 \mu \mathrm{g} / \mathrm{mL}$ ethidium bromide, and visualized under ultraviolet light, then photographed. DNA fragment sizes were determined by comparisons with the $1 \mathrm{~kb}$ DNA ladder marker (Takara Cat log no- 57034). The presence and absence of amplified fragments from each primer were scored respectively as " 1 " and " 0 " for each treatment group.

Table 2. Name and sequence of the primers used in ISSR detection.

\begin{tabular}{|c|c|c|c|}
\hline Primer code & Sequence & Primer code & Sequence \\
\hline ISSR 1 & $(\mathrm{AG})_{8} \mathrm{YC}$ & $\mathrm{HB}_{11}$ & $(\mathrm{GT})_{6} \mathrm{CC}$ \\
\hline ISSR 2 & $(\mathrm{AG})_{8} \mathrm{YG}$ & $\mathrm{HB}_{12}$ & $(\mathrm{CAC})_{3} \mathrm{GC}$ \\
\hline ISSR 3 & $(\mathrm{AC})_{8} \mathrm{YT}$ & $\mathrm{HB}_{13}$ & $(\mathrm{GAG})_{3} \mathrm{GC}$ \\
\hline ISSR 5 & $(\mathrm{GT})_{8} \mathrm{YG}$ & Sh 2 & $(\mathrm{AG})_{8} \mathrm{CTG}$ \\
\hline ISSR 6 & $\mathrm{CGC}(\mathrm{GATA})_{4}$ & Sh 3 & $(\mathrm{AC})_{8} \mathrm{CTT}$ \\
\hline ISSR 7 & GAC(GATA $)_{4}$ & Sh 4 & $(\mathrm{AC})_{8} \mathrm{CTG}$ \\
\hline ISSR 9 & $(\mathrm{GATA})_{4} \mathrm{GC}$ & Issr2(h) & $\mathrm{CAC}(\mathrm{TCC})_{5}$ \\
\hline ISSR 10 & $(\mathrm{GACA})_{4} \mathrm{AT}$ & Sh 6(h) & $\mathrm{CGC}(\mathrm{GATA})_{4}$ \\
\hline $814_{\mathrm{A}}$ & $(\mathrm{CT})_{8} \mathrm{TG}$ & Sh 7(h) & GAC(GATA $)_{4}$ \\
\hline $844_{\mathrm{A}}$ & $(\mathrm{CT})_{8} \mathrm{AC}$ & Sh $8(h)$ & $(\mathrm{AGAC})_{4} \mathrm{GC}$ \\
\hline $844_{B}$ & $(\mathrm{CT})_{8} \mathrm{GC}$ & Sh 9(h) & $(\mathrm{GATA})_{4} \mathrm{GC}$ \\
\hline $17898_{\mathrm{A}}$ & $(\mathrm{CA})_{6} \mathrm{AC}$ & Issr3(h) & TTT(TCC) $)_{5}$ \\
\hline $17899_{\mathrm{A}}$ & $(\mathrm{CA})_{6} \mathrm{AG}$ & Issr10(h) & $(\mathrm{TCC})_{5} \mathrm{NAC}$ \\
\hline $\mathrm{HB}_{9}$ & $(\mathrm{GT})_{6} \mathrm{GG}$ & & \\
\hline
\end{tabular}

\subsection{Statistical Analyses}

The experiment is designed as a complete randomized design. The data from all measurements are analyzed with ANNOVA/MANOVA of Statistica 6 software (Statsoft, 2001). The significance of mean difference among the treatment groups were tested at probability level of $p=0.05$.

\section{Results}

Shoots emerged simultaneously from rhizomes of all treatment groups four weeks after sowing with $100 \%$ emergence rate in all groups (control, 5-, 10-, and 15- min laser irradiation). After three months of cultivation, all the plants derived from the 5 min laser treated rhizomes showed yellowing and eventually died (in both planting seasons). Therefore, no growth parameters and GC-MS data were available for the $5 \mathrm{~min}$ treatment group.

\subsection{Vegetative Growth and Yield}

The means of the vegetative growth parameters are presented in tables 3 and 4. Data showed that in both seasons, there are significant changes in the plant height, root numbers, and dried weight of leaves and roots for plants in the laser treatment groups as compared with control. Leaves number in the plants from laser irradiated groups increased as compared to control; however, the increase is not statistically significant. The $10 \mathrm{~min}$ laser treatment group showed highest measurement in all parameters as compared to the control and 15 min laser treatment groups in both seasons (Table 3 ).

In term of yields, the number of rhizomes in laser treated groups were slightly higher than that of the control group; however, the difference was statistically insignificant. On the other hand, a drastic increase in the rhizome dried weight was observed in the laser treated groups (10 and $15 \mathrm{~min}$ ) as compared to the control group in both planting seasons. Increase in rhizome dried weight in the laser treated groups (10 and $15 \mathrm{~min}$ ) was accompanied with the increase in rhizome diameters. The highest rhizome dry weight (41 and $27.2 \mathrm{~g}$ ) and rhizome diameters $(23.28$ and $19.01 \mathrm{~mm})$ were obtained with $10 \mathrm{~min} \mathrm{He}-\mathrm{Ne}$ laser treatment and the lowest rhizome dry weight (15 and $9.3 \mathrm{~g}$ ) and rhizome diameters (13 and $16 \mathrm{~mm})$ were observed in the control treatment in the first and second season respectively. An increase of more than $100 \%$ in rhizome dried weight were observed in both $10 \mathrm{~min}$ and $15 \mathrm{~min}$ laser treated groups as compared to control group (Table 4). 
Table 3. Effects of laser treatment on the plant height (cm), number (n) of leaves and roots, dried weight (g) of leaves and roots of Curcuma longa.

\begin{tabular}{|c|c|c|c|c|c|c|c|c|c|c|}
\hline \multirow{2}{*}{ Laser treatments } & \multicolumn{2}{|c|}{ Plant height (cm) } & \multicolumn{2}{|c|}{ No. of Leaves (n) } & \multicolumn{2}{|c|}{ No. of roots (n) } & \multicolumn{2}{|c|}{ Leaves dried weight (g) } & \multicolumn{2}{|c|}{ Roots dried weight (g) } \\
\hline & 2016 & 2017 & 2016 & 2017 & 2016 & 2017 & 2016 & 2017 & 2016 & 2017 \\
\hline Control & $152.33 b^{*}$ & $154.25 \mathrm{~b}$ & $11.75 \mathrm{a}$ & $10.25 \mathrm{a}$ & $23 \mathrm{~b}$ & $23.67 \mathrm{~b}$ & $27.28 \mathrm{c}$ & $24.03 \mathrm{c}$ & $4.31 \mathrm{~b}$ & $3.84 \mathrm{~b}$ \\
\hline $10 \mathrm{~min}$ & $167.88 \mathrm{a}$ & $174.50 \mathrm{a}$ & $12.67 \mathrm{a}$ & $15.0 \mathrm{a}$ & $38.5 \mathrm{a}$ & $36.2 \mathrm{a}$ & $60.0 \mathrm{a}$ & $39.43 b$ & $6.05 \mathrm{a}$ & $6.52 \mathrm{a}$ \\
\hline $15 \mathrm{~min}$ & $164.50 \mathrm{a}$ & $173.00 \mathrm{a}$ & $10.00 \mathrm{a}$ & $12.75 \mathrm{a}$ & $30 \mathrm{~b}$ & $29.3 \mathrm{ab}$ & $43.8 \mathrm{~b}$ & $48.68 \mathrm{a}$ & $5.76 \mathrm{ab}$ & $5.96 \mathrm{~b}$ \\
\hline
\end{tabular}

* Means followed by the same letter within a column are not significantly different at 0.05 level of probability according to L.S.D. test

Table 4. Effects of laser treatment on the number (n) of rhizomes, rhizomes dried weight (g), and rhizome diameter (mm) of Curcuma longa.

\begin{tabular}{lllllll}
\hline \multirow{2}{*}{ Laser treatments } & \multicolumn{2}{l}{ No. of rhizomes $(\mathbf{n})$} & \multicolumn{2}{l}{ Rhizome dried weight (g) } & \multicolumn{2}{l}{ Rhizome diameters (mm) } \\
\cline { 2 - 7 } & $\mathbf{2 0 1 6}$ & $\mathbf{2 0 1 7}$ & $\mathbf{2 0 1 6}$ & $\mathbf{2 0 1 7}$ & $\mathbf{2 0 1 6}$ & $\mathbf{2 0 1 7}$ \\
\hline Control & $16 \mathrm{a}^{*}$ & $16.67 \mathrm{a}$ & $15 \mathrm{~b}$ & $9.37 \mathrm{~b}$ & $13.08 \mathrm{c}$ & $16.15 \mathrm{~b}$ \\
$10 \mathrm{~min}$ & $17.75 \mathrm{a}$ & $18.13 \mathrm{a}$ & $41.1 \mathrm{a}$ & $27.2 \mathrm{a}$ & $23.28 \mathrm{a}$ & $19.01 \mathrm{a}$ \\
$15 \mathrm{~min}$ & $17 \mathrm{a}$ & $11.6 \mathrm{a}$ & $34.43 \mathrm{a}$ & $21.63 \mathrm{a}$ & $18.09 \mathrm{~b}$ & $18.01 \mathrm{a}$ \\
\hline
\end{tabular}

* Means followed by the same letter within a column are not significantly different at 0.05 level of probability according to L.S.D. test

\subsection{Plant pigments Analysis}

The data in table 5 show that both 10 and 15 min He-Ne laser rays treatments affected positively and significantly on chlorophyll a, b and carotenoid contents as compared with control treatment. The 10 min He-Ne laser treatment gave higher measurement as compared to $15 \mathrm{~min} \mathrm{He}-\mathrm{Ne}$ laser treatment in all the recorded parameters.

Table 5. Effects of laser treatment on the chlorophyll a (chl a), b (chl b), and carotenoid contents of Curcuma longa leaves.

\begin{tabular}{llllll}
\hline \multirow{2}{*}{ Laser treatments } & \multicolumn{2}{l}{ Chl a (mg/100g F.W.) } & \multicolumn{2}{c}{ Chl b (mg/100g F.W.) } & Carotenoids (mg/100g F.W.) \\
\cline { 2 - 6 } & $\mathbf{2 0 1 6}$ & $\mathbf{2 0 1 7}$ & $\mathbf{2 0 1 6}$ & $\mathbf{2 0 1 7}$ & $\mathbf{2 0 1 6}$ \\
\hline Control & $70.82 \mathrm{~b} *$ & $46.39 \mathrm{~b}$ & $24.19 \mathrm{~b}$ & $14.35 \mathrm{c}$ & $93.09 \mathrm{~b}$ \\
10 min & $82.12 \mathrm{a}$ & $74.85 \mathrm{a}$ & $27.30 \mathrm{a}$ & $25.49 \mathrm{a}$ & $101.79 \mathrm{a}$ \\
15 min & $74.29 \mathrm{~b}$ & $47.39 \mathrm{~b}$ & $25.20 \mathrm{~b}$ & $19.50 \mathrm{~b}$ & $98.21 \mathrm{ab}$ \\
\hline
\end{tabular}

* Means followed by the same letter within a column are not significantly different at 0.05 level of probability according to L.S.D. test

\subsection{ISSR-PCR Analysis}

DNA samples from plants of all treatment groups (control, 5-, 10- and 15 min laser irradiation) were analyzed using 31 primers (Table 2). Out of 31 primers used, 9 primers were found to produce clear amplified bands (Figure 1). The total number of amplified amplicons was 65 and the number of amplified DNA fragments by each primer ranged from 5 to 12 fragments (Table 6). SH8 ISSR primer amplified the highest number of fragments (12 bands), while ISSR9 primers produced the lowest number of amplicons ( 5 bands) (Table 6 ). The percentage of polymorphism as revealed by the different primers ranged from $0 \%$ for ISSR 9 primer to $77.8 \%$ for $\mathrm{SH} 7$ (h) primer. ISSR3, SH7 and SH8 ISSR primers were found to produce specific markers with different molecular sizes (2800, $2230,1170,910,280,560,550,430$ and $250 \mathrm{bp}$ ) (Table 6 and 7). Our results suggested that laser irradiation resulted in DNA polymorphism in the rhizomes.

Table 6. Number of amplified fragments (AF), monomorphic bands (MB), polymorphic bands (PB), percentage of polymorphic bands (PB\%) and specific markers (SM) of 4 Curcuma longa plants from various laser treatments based on ISSR-PCR analysis with 9 primers.

\begin{tabular}{|c|c|c|c|c|c|c|c|c|c|c|c|}
\hline \multirow{2}{*}{\multicolumn{2}{|c|}{ Laser treatments }} & \multicolumn{10}{|c|}{ Primer } \\
\hline & & SH1 & SH7 (h) & SH8 (h) & ISSR2 (h) & ISSR3 & ISSR5 & ISSR8 & ISSR9 & 17898A & Total \\
\hline \multirow{2}{*}{ Control } & $A F$ & 6 & 5 & 8 & 4 & 7 & 7 & 5 & 5 & 6 & 53 \\
\hline & $S M$ & 0 & 2 & 3 & 0 & 1 & 0 & 0 & 0 & 0 & 6 \\
\hline \multirow{2}{*}{$5 \mathrm{~min}$} & $A F$ & 6 & 5 & 7 & 6 & 6 & 5 & 4 & 5 & 6 & 50 \\
\hline & $S M$ & 0 & 0 & 0 & 0 & 0 & 0 & 0 & 0 & 0 & 0 \\
\hline \multirow{2}{*}{$10 \mathrm{~min}$} & $A F$ & 4 & 6 & 7 & 5 & 5 & 7 & 4 & 5 & 6 & 49 \\
\hline & $S M$ & 0 & 0 & 0 & 0 & 0 & 0 & 0 & 0 & 0 & 0 \\
\hline $15 \mathrm{~min}$ & $S M$ & 0 & 1 & 1 & 0 & 0 & 0 & 1 & 0 & 0 & 3 \\
\hline \multirow{5}{*}{ Total } & $A F$ & 6 & 9 & 12 & 7 & 7 & 7 & 6 & 5 & 6 & 65 \\
\hline & $M B$ & 4 & 2 & 2 & 1 & 5 & 5 & 3 & 5 & 6 & 33 \\
\hline & $P B$ & 2 & 7 & 10 & 6 & 2 & 2 & 3 & 0 & 0 & 32 \\
\hline & $P B \%$ & 33.3 & 77.8 & 83.3 & 85.7 & 28.6 & 28.6 & 50.0 & 0 & 0 & 49.2 \\
\hline & $S M$ & 0 & 3 & 4 & 0 & 1 & 0 & 1 & 0 & 0 & 9 \\
\hline
\end{tabular}


Table 7. Estimated molecular size (bp) of specific markers amplified by 9 primers using the DNA samples from curcuma plants from different laser treatments.

\begin{tabular}{lllll}
\hline \multirow{2}{*}{ Laser treatments } & \multicolumn{1}{l}{ ISSR primers } & & & \\
\cline { 2 - 5 } & SH7 (h) & SH8 (h) & ISSR3 & \\
\hline \multirow{2}{*}{ Control } & 1170 & 2230 & 2800 & \\
& 550 & 430 & & \\
$5 \mathrm{~min}$ & & & & 560 \\
$10 \mathrm{~min}$ & & 280 & & \\
15 min & 250 & 280 & & \\
\hline
\end{tabular}
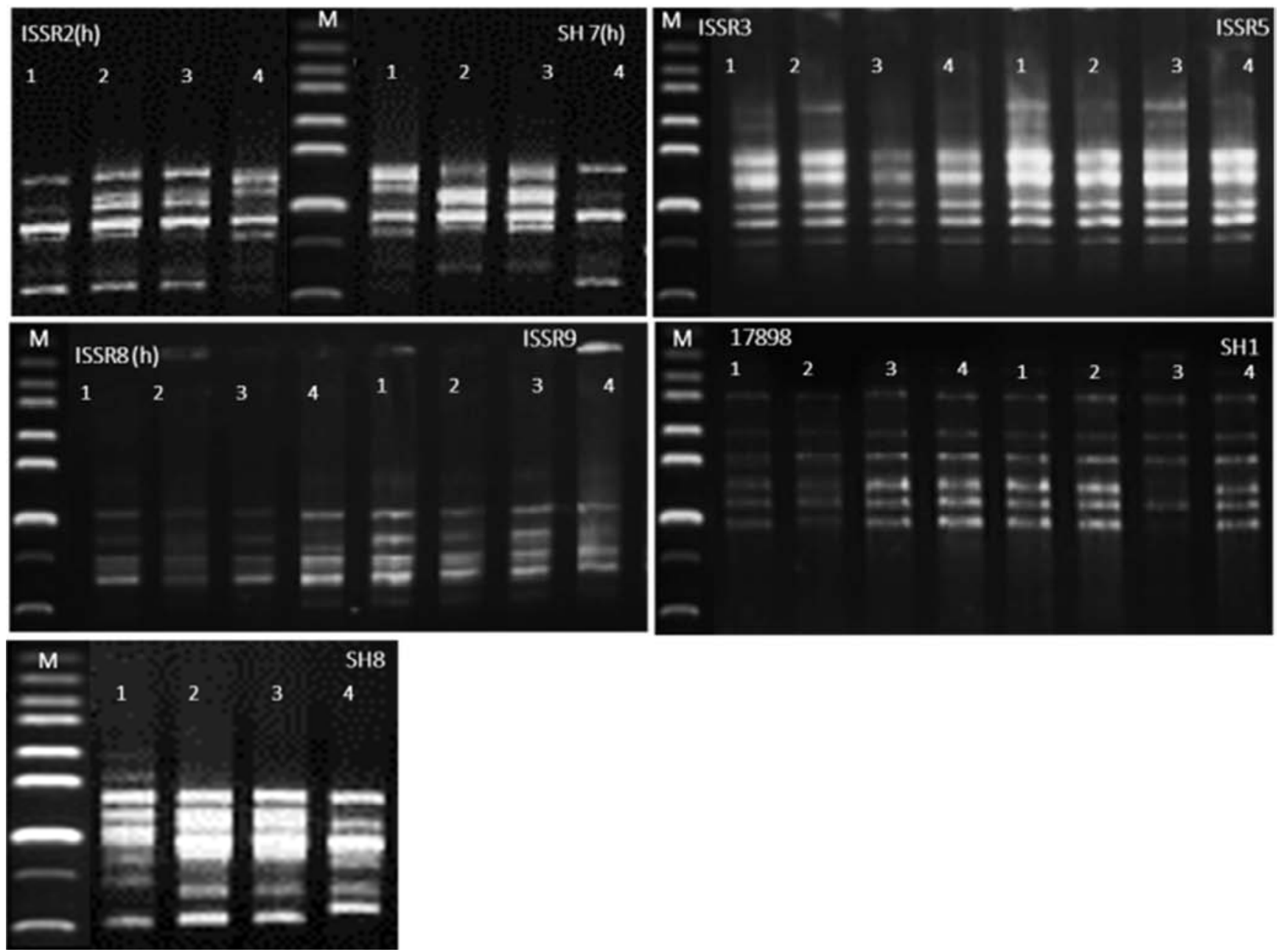

Figure 1. ISSR-PCR patterns of Curcuma longa with 9 primers. Lane $M$ contain the DNA marker (1Kb DNA ladder, Takara), while those of s1, 2, 3 and 4 are $P C R$ products from DNA samples from control, $5 \mathrm{~min}, 10 \mathrm{~min}$, and $15 \mathrm{~min}$ laser treatment plants respectively.

\subsection{GC/MS Analysis}

Phytochemicals present in the ethanol extracts prepared from the rhizomes of the 3 treatment groups (control, 10- and $15 \mathrm{~min}$ laser irradiation) were analyzed by gas chromatography-mass spectrometry (Table 8 , Figure 2). The predominant constituents such as curcumin, eucalyptol, tumerone and curcumene were found at different retention time in all treatment groups. Our results have revealed that laser pre-treatment alter the phytochemical compositions of the ethanol extracts from the newly developed rhizomes produced by the curcuma plants. The caryophyllene peak at retention time $27.78 \mathrm{~min}$ were presented only in plants treated with laser for $15 \mathrm{~min}$. Rhizomes produced from the plant treated with $15 \mathrm{~min}$ had higher curcumin and curcumene percentage as compared to control and $10 \mathrm{~min}$ laser treatment, while the $10 \mathrm{~min}$ laser treated plants produced the highest percentage of eucalyptol and turmerone compounds (Table 8 and Figure 2). 
RT: $6.02 \cdot 28.55$ SM: $7 B$

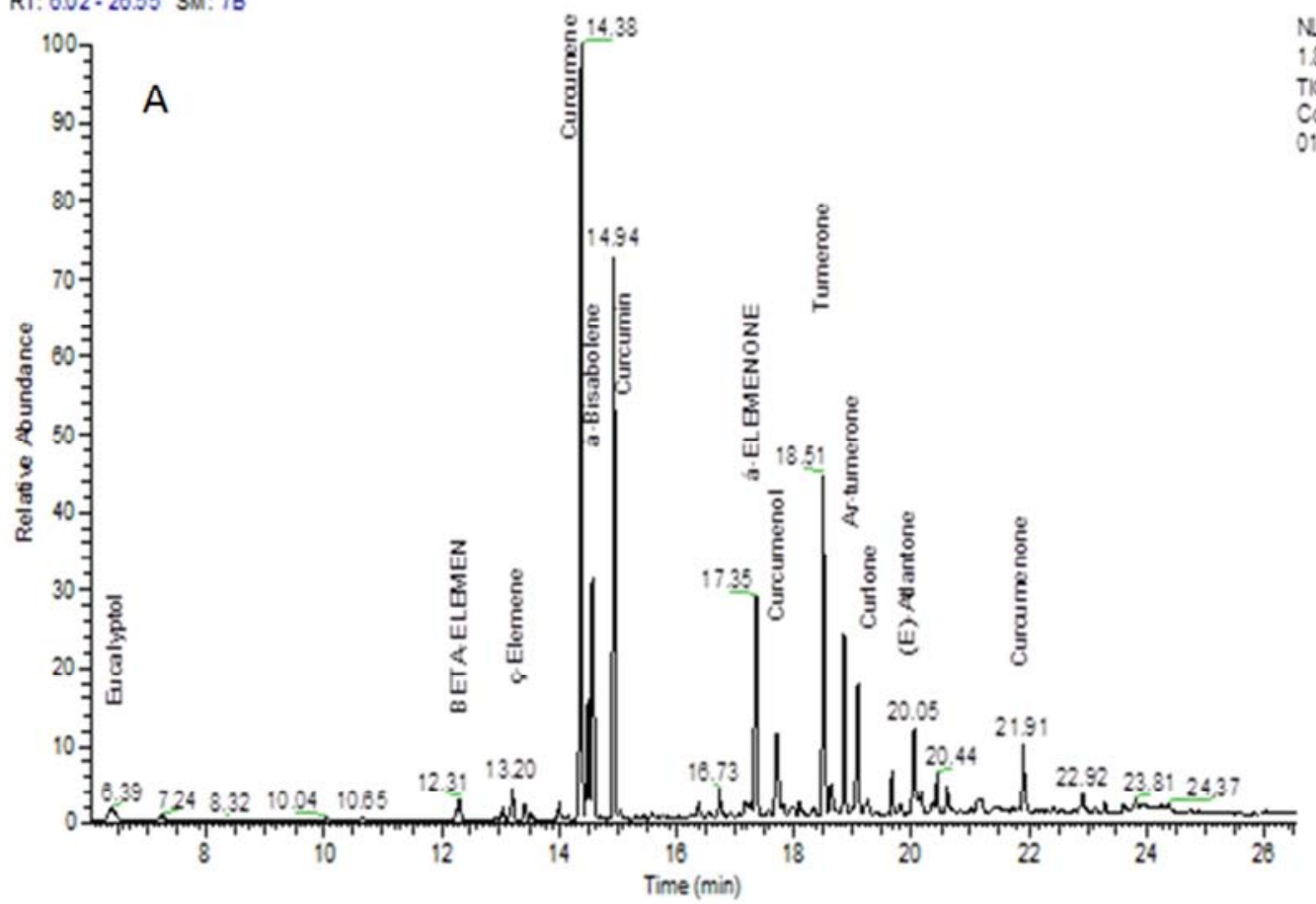

$\mathrm{N}:$

$189 E 9$

C MS

Contol:R2.
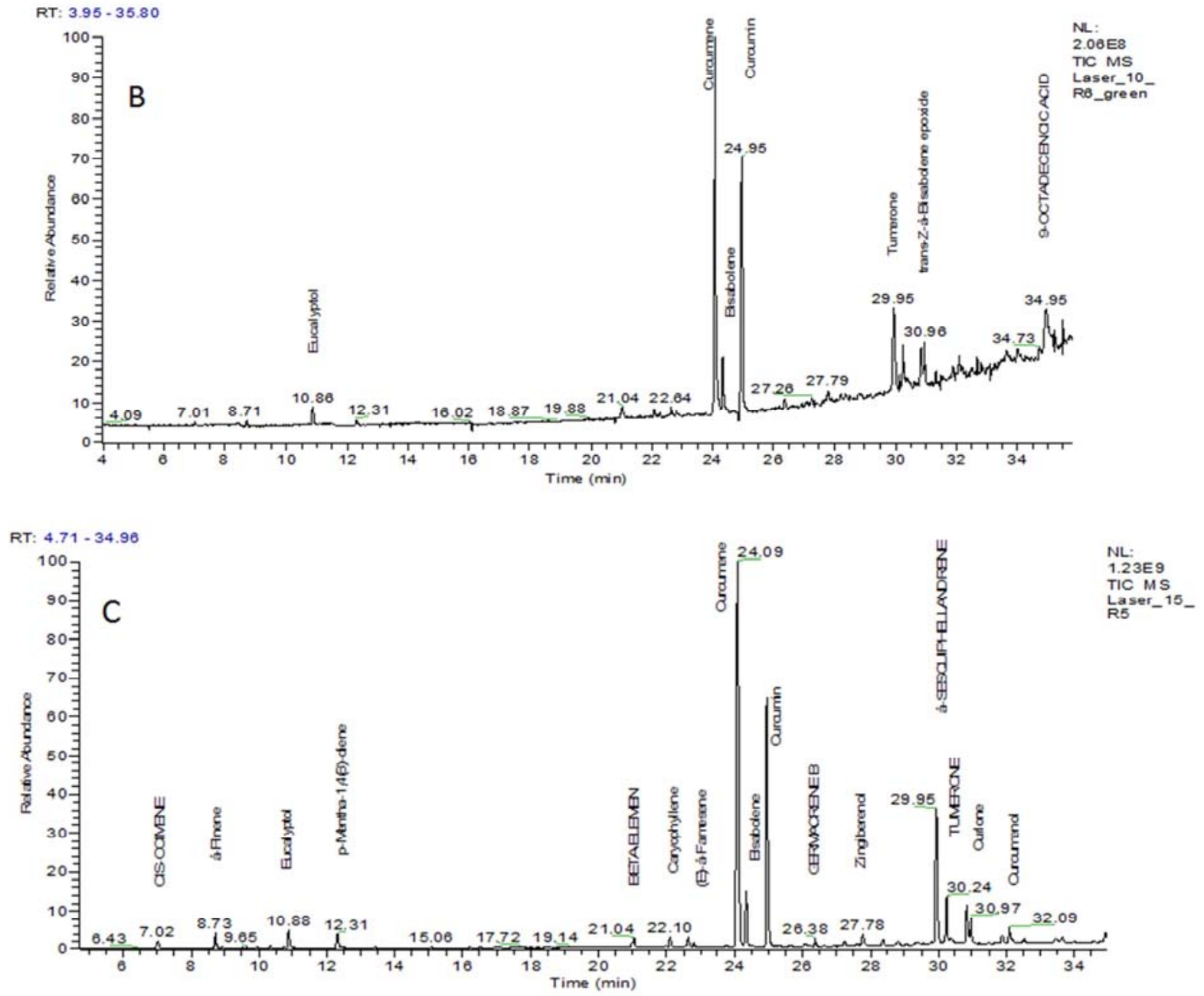

Figure 2. The chemical compositions of ethanol extract from Curcuma longa rhizome analyzed by gas chromatography-mass spectrometry. (A) Extract from control plants. (B) Extract from 10 min laser treated plants. (C) Extract from 15 min laser treated plants. 
Table 8. Components identified by gas chromatography-mass spectrometry in the Curcuma longa rhizome ethanol extract from the control, 10 - and 15 min laser treatment groups.

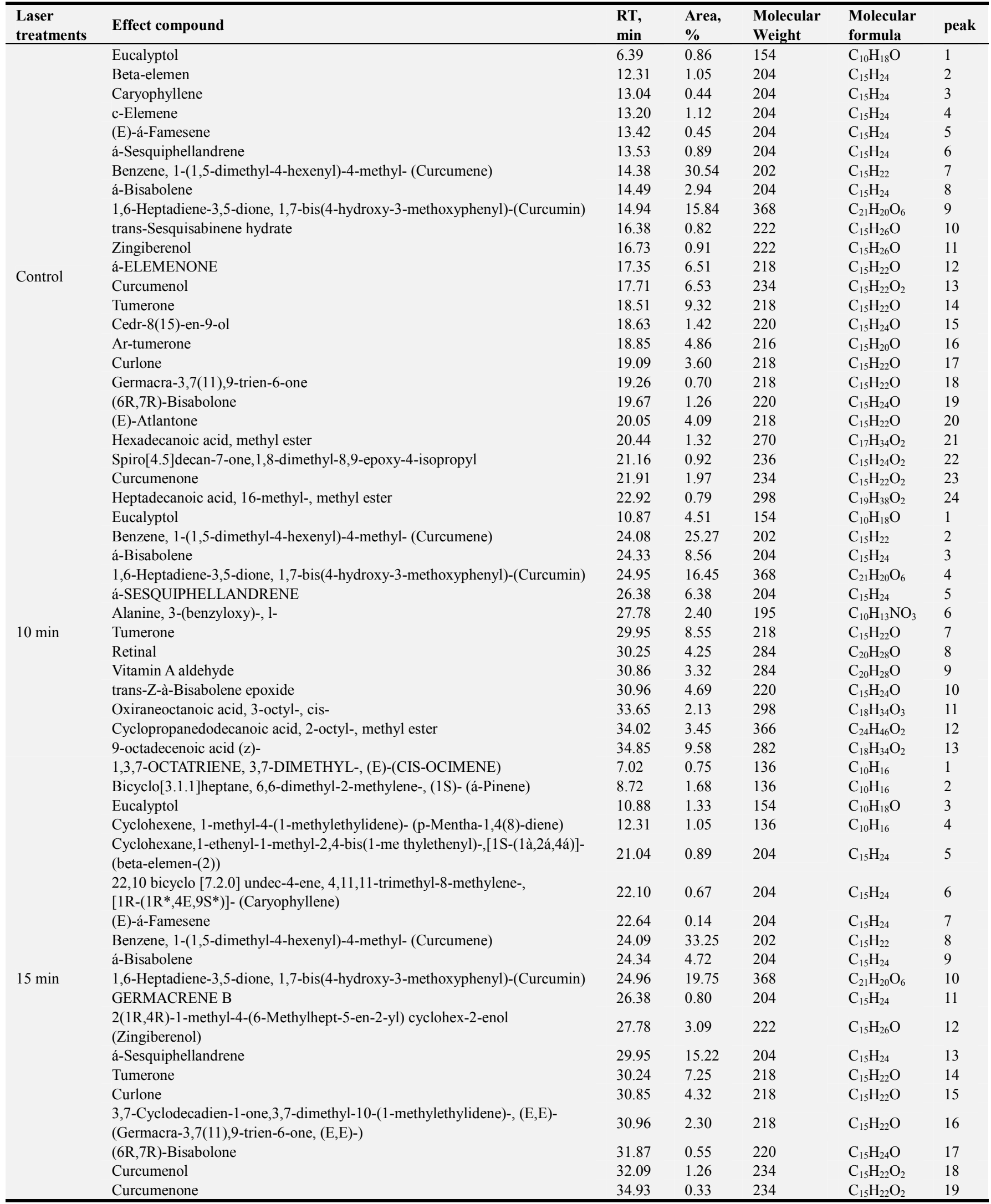




\section{Discussion}

Laser bio-stimulation effects on plant growth was first reported in 1970 [6] and subsequently supported by many studies in various plant species ranging from crops to vegetables and herbs [7, 9, 11-16, 32].

Our study has indicated that He-Ne laser pretreatment on rhizomes have enhanced curcuma plant growth and rhizomes yield as observed in the significance increase in plant height, number of roots, dried weight of leaves, roots, and rhizome as well as average rhizome diameters in both 10 - and $15 \mathrm{~min}$ laser treatment groups as compared to the control group. The increase in plant growth and rhizomes yield is accompanied by the significant increase in plant photosynthetic pigments such as chlorophyll a and $b$. We have observed that $10 \mathrm{~min}$ laser irradiation resulted in higher enhancement effects in the above-mentioned parameters as compared to the $15 \mathrm{~min}$ irradiation treatment. It is worthy to point out that our study has revealed a tremendous increase (more than 100\%) in rhizomes yield in both 10 - and 15 min laser treatment groups as compared to the control group. Our results have shown that laser pre-treatment on the vegetative organ (rhizomes) have similar long-term plant growth and yield enhancement effects as reported in an early study by Vasilevski and Bosev [33] on laser pre-treated potato tuber and those from many other studies using pre-sowing laser irradiated seeds $[9,11,16-18$, $32,34]$.

In addition to the morphological growth and yield enhancement effects, biochemical and physiological changes have also been observed during the germination and various growth stages in numerous plant species. These changes includes alteration of macro nutrients (such as carbohydrate, fat, protein, and nitrogen), and various minerals contents [11, 14, 18], increase in specific activities of antioxidative (catalase, superoxide dismutase, peroxidase) and degradative (amylase and protease) enzymes [10, 11, 35], increase in indole-3-acetic acid (IAA) contents [32, 35] and enhance photosynthetic rate and transpiration rate [11].

The mechanisms leading to enhance seed germination and seedling growth as resulted from pre-sowing laser seeds treatment have been proposed by different research groups. These proposals include the increase of potential energy of seeds, the activation of phytochromes (light receptor) and phytohormone such as gibberellic acid $\left(\mathrm{GA}_{3}\right)$ and Indoacetic acids (IAA). [7]. However, there are still gaps to be filled in order to understand the mechanisms that lead to all these effects resulted from pre-sowing seeds or vegetative organs (rhizomes or tubers) treatment.

Light is one of the environment factors that affect secondary metabolites synthesis [36, 37]. Shiga, Shoji [38] have reported that red light illumination enhanced Rosmarinic acid content and antioxidant activities in Ocimum basilicum $\mathrm{L}$ plants as compared to blue light illumination. Studies from soy beans [9], sweet basil [16], fennel and coriander [17], anise and cumin [18] also indicated that seeds produced from plants grown from pre-sowing laser irradiated seeds contained higher essential oils contents as compared to that produced from the control plants derived from untreated seeds. The authors have attributed the increase in essential oil contents partly as the result of increased growth and metabolisms. Our study has revealed that laser pre-treatment has altered the phytochemical compositions of the newly emerged rhizomes produced from the plants in the laser treatment groups. However, further investigations are needed to understand the underlying mechanisms that cause the variation in phytochemical compositions of rhizomes from different laser pre-treatment groups.

A recent study by Qiu et al [8] to investigate the drought response of one week-old wheat seedlings derived from pre-sowing laser irradiated seeds at both physiological and transcriptome level have revealed that transcripts related to photosynthesis, nutrient uptake and transport, homeostasis control of reactive species, and transcriptional regulation were expressed predominantly in seedling from the pre-sowing laser irradiated seeds. These finding has provided strong evidence to support the biochemical and physiological effects that were previously observed during the germination and early seedling stage in the studies with pre-sowing laser treated seeds. On the other hand, an early study by Metwally, Abou-Ellail [12] have also reported on differential protein expression in Celosia argentea in the late growth stage (90 days post planting) of plants grown from pre-sowing laser irradiated seeds. However, it remains unclear on whether the observation from Metwally, Abou-Ellail [12] was due to transcriptional activation or a change at the gene level as a result from the pre-sowing seed laser irradiation.

Nevertheless, our study is the first report which investigate the effect of laser at the DNA level by using ISSR marker. Interestingly, we have found that laser pre-treatment on rhizomes have resulted in DNA polymorphism in the plants derived from the laser treated rhizomes. However, based on our current data, we could not establish the causal relationship between the DNA polymorphism to the observed growth and yield enhancement, nor the alteration of the chemical composition of the ethanol extracts from the rhizomes.

\section{Conclusion}

Our study has indicated that laser irradiation on the vegetative organ (rhizomes) of curcuma has enhanced the growth of the resulting curcuma plants and subsequently lead to more than $100 \%$ increase in the rhizomes yield. In addition, changes in phytochemicals composition in the rhizomes produced by plants derived from laser pre-treated vegetative organs was also observed. Based on the ISSR analyses using 31 primers, we have observed genetic variation in the plants derived from laser pre-treated rhizomes as compared to control plants. These observations open new challenges to be addressed in order to understand the mechanisms involved in laser bio-stimulation effects on plants. 


\section{Acknowledgements}

The authors would like to thank Dr. Salah Khattab (Department of Biological Sciences) and the Department of Physics, Faculty of Science, King Faisal University, Al-Ahsaa The Kingdom of Saudi Arabia, for their kind help and assistance. Support of the Agricultural-Veterinarian Training and Research Station, King Faisal University, Al-Ahsaa, The Kingdom of Saudi Arabia.

\section{References}

[1] Prasad, S. and B. B. Aggarwal, Turmeric, the goldern spice From traditional medicine to modern medicine, in Herbal Medicine: Biomolecular and Clinical Aspects, I. F. F. Benzie and S. Wachtel-Galor, Editors. 2011, CRC Press.

[2] Gupta, S., G. Kismali, and B. Aggarwal, Curcumin, a component of turmeric: from farm to pharmacy (Review). Biofactor, 2013. 39 (1): p. 2-13.

[3] Paramasivam, M., et al., High performance thin layer chromatographic method for quantitative determination of curcuminoids in Curcuma longa germplasm. Food Chem, 2009 113 (2): p. 640-644.

[4] Amalraj, A., et al., Biological activities of curcuminoids, other biomolecules and their derivatives - A review J Tradit. Complement Med. 7, 2017. 2: p. 205-233.

[5] Wilde, W. H. A., W. H. Parr, and D. W. McPeak, Seed bask in laser light. Laser Focus, 1969. 5 (23): p. 41-42.

[6] Paleg, L. and D. Aspinall, Field control of plant growth and developemnt through the laser activation of phytochrome. Nature, 1970. 5275: p. 970-975.

[7] Hernández, A., et al., Laser in agriculture. International Agrophysics, 2010. 24: p. 407-422.

[8] Qiu, Z., et al., Physiological and transcriptome analysis of He-Ne laser pretreated wheat seedlings in response to drought stress. Sci Rep, 2017.7 (1): p. 6108.

[9] Asghar, T., et al., Comparison of HeNe laser and sinusoidal non-uniform magnetic field seed pre-sowing treatment effect on Glycine max (Var 90-I) germination, growth and yield. J Photochem Photobiol B, 2017. 166: p. 212-219.

[10] Asghar, T., et al., Laser light and magnetic field stimulation effect on biochemical, enzymes activities and chlorophyll contents in soybean seeds and seedlings during early growth stages. J Photochem Photobiol B, 2016. 165: p. 283-290.

[11] Perveen, A., et al., He-Ne laser-induced improvement in biochemical, physiological, growth, and yield characteristics in sunflower (Helianthus annus L.) Photochem. Photobiol., 2011. 87 (6): p. 1454-1463.

[12] Metwally, S. A., et al., Effect of laser raiation on he growht, anatomical and biochemical genetic markers of Celosia argentea plants. International Journal of Academic Research Part A, 2013.5 (3): p. 200-206.

[13] Nasiri, A. A., F. Mortazaeinezhad, and R. Taheri, Seed germination of medicinal sage is affected by gibberellic acid, magnetic field and laser irradiation. Electromagnetic biology and medicine, 2018. 37 (1): p. 50-56.
[14] Urva, et al., Low power continuous wave-laser seed irradiation effect on Moringa oleifera germination, seedling growth and biochmical attributes. Journal of Photochemistry and Photobiology, B: Biology, 2017. 170: p. 314-423.

[15] Krawiec, M., et al., Laser irradiation effect on scorzonera (Scorzonera hispanica L.) seed germination and seedling emergence. Acta Sci. Pol. Hortorum Cultus, 2015. 14 (2): p. 145-158.

[16] El-Kereti, M. A., et al., ZnO nanofertilizer and He Ne Laser irradiation for promoting growth and yield of sweee basil plant. Recent Patents on Food, Nutrition and Agriculture, 2013. 5 (3): p. 169-181.

[17] Osman, Y. A. H., K. M. E. Tobgy, and E. S. A. E. Sherbini, Effect of laser radiation treatments on growth, yield and chemical constituents of fennel and coriader plants. Journal of Applied Sciences Research, 2009. 5 (3): p. 244-252.

[18] Tobgy, K. M. K. E., Y. A. H. Osman, and E. S. A. E. Sherbini, Effect of laser radiation on growth, yield and chemical constitutuents of anise and cumin plants. Journal of Applied Sciences Research, 2009. 5 (5): p. 522-528.

[19] Nadeem, M. A., et al., DNA molecular markers in plant breeding: current status and recent advancements in genomic selection and genome editing. Biotechnology and Biotechnological Equipment, 2018. 32 (2): p. 261-285.

[20] Sarwat, M., et al., Molecular markers in medicinal plant biotechnology: past and present. Critical Review in Biotechnology, 2011. 32 (1): p. 74-92.

[21] Idrees, M. and M. Irshad, Molecular markers in plants for analysis of genetics diversity: A Review. European Academic Research, 2014. II (1): p. 1513-1540.

[22] Sharma, P., et al., Polymorphism analysis in advanced mutant population of oat (Avena sativa L.) using ISSR markers. Physiol Mol Bio Plants, 2016. 22 (1): p. 115-120.

[23] Mostafa, G. G., A. M. Alfrmawy, and H. E. El-Mikadem, Induction of mutation in Celosia argentea using Dimethyl Sulphate and identification of genetic variation by ISSR markers. International Journal of Plant Breeding and Genetics, 2014. 8 (2): p. 44-56.

[24] ZakyZayed, M., et al., EMS- induced mutagenesis and DNA polymorphism assessment through ISSR markers in Neolamarckia cadamba (kelampayan) and Leucaena lecocephala (petai belalang). European Journal of Experimental Biology, 2014. 4 (4): p. 156-163.

[25] El-Mahrouk, M. E.-S., et al., Morphological and molecular characterization of induced mutants in Nigella sativa L. using irradiation and chemical mutagens. Egypt. J. Plant Breed 2015. 19 (3): p. 257-272.

[26] Tomlekova, N., et al., Molecular identification of tomato mutant lines. Bioremediation, biodiversity and bioavailability 2012. 6 (special issues 1): p. 58-64.

[27] Singh, S., M. K. Panda, and S. Nayak, Evaluation of genetic diversity in turmeric (Curcuma longa L.) using RAPD and ISSR markers Industrial Crops and Products, 2012. 37: p. 284-291.

[28] Saha, K., et al., ISSR fingerprinting to ascertain the genetic relationship of Curcuma sp. of Tripura. American Journal of Plant Sciences, 2016 (7): p. 259-266. 
[29] A. O. A. C, Official Method of Analysis of the Association of Officail Chemist., in Official Methods of Analysis, Howitz, Editor. 1984, Association of Officail Analytical Chemist: P. O. Box 540, Benjamin Franklin Station, Washington DC 200400.

[30] Salem, Z. M., et al., Chemical composition, antioxidant and antibacterial activities of extracts from Schinus molle wood branch growing in Egypt. Journal of Wood Science, 2016. 62: p. 548-561.

[31] Adams, R., Identification of essential oil components by gas chromatography/mass spectroscorpy. 4 ed. 2007, Carol Stream: Allured Publishing.

[32] Podleśna, A., et al., Changes in the germination process and growth of pea in effect of laser seed irradiation. International Agrophysics, 2015. 29 (4): p. 485-492.

[33] Vasilevski, G. and D. Bosev, Results of the effect of laser light on some vegetables. Acta Hortic., 1997. 462: p. 473-476.
[34] Koper, R., et al., Effect of the laser exposure of seeds on the yield and chemical composition of sugar beet roots. Int. Agrophysics, 1996. 10: p. 103-108.

[35] Podleśny, J., et al., Effect of laser light treatment on some biochemical and physiological processes in seeds and seedlings of white lupine and faba bean. Plant Growth Regulation, 2012. 67 (3): p. 227-233.

[36] Yang, L., et al., Response of Plant Secondary Metabolites to Environmental Factors. Molecules, 2018. 23 (4).

[37] Thakur, M., et al., Improving production of plant secondary metabolites through biotic and abiotic elicitation. Journal of Applied Research on Medicinal and Aromatic Plants, 2018.

[38] Shiga, T., et al., Effect of light quality on rosmarinic acid content and antioxidant activity of sweet basil, Ocimum basilicum. Plant Biotechnology, 2009. 26: p. 255-259. 